\title{
Chlorination of o-Cresoxyacetic Acid
}

\author{
A Peculiar Side Reaction
}

\author{
H A K O N L U N D
}

Chemical Institute, Aarhus University, Denmark

\begin{abstract}
When o-cresoxyacetic acid is chlorinated in an organic solvent 4-chloro-2-methyl-phenoxyacetic acid is the main product, but a small amount of material which is insoluble in aqueous alkali is simultaneously formed. A compound, $\mathrm{C}_{9} \mathrm{H}_{9} \mathrm{O}_{3} \mathrm{Cl}_{3}$, has been isolated and is shown to be a cyclic ester-acetal of glycolic acid and 2-methyl-4,5,6trichloro-cyclohex-2-en-1-one.
\end{abstract}

$\mathrm{T}^{\mathrm{s}}$ he "weed-killer" 2-methyl-4-chloro-phenoxyacetic acid is industrially prepared by chlorination of $o$-cresoxyacetic acid in an organic solvent ${ }^{1}$. The acid is extracted by means of aqueous alkali. In the organic solvent remains, however, a small quantity of material which is not directly soluble in aqueous alkali. After removal of the solvent in vacuo a rather viscous oil is obtained which, on cooling, partially crystallizes. Filtration is almost impossible; but when the hot oil is diluted with alcohol a well-defined compound A, m.p. $137^{\circ}$, is easily isolated. From the dark mother liquor a mixture of compounds can be obtained by distillation at $0.5-1 \mathrm{~mm}$ pressure. The percentage composition of this material is the same as that of compound A and corresponds to the formula $\mathrm{C}_{9} \mathrm{H}_{9} \mathrm{O}_{3} \mathrm{Cl}_{3}$. Apparently the material is a mixture of isomers of $\mathrm{A}$.

Compound $\mathrm{A}$ can be isolated in an amount of about $30 \%$ of the total product. The constitution of $\mathrm{A}$ seems to be<smiles>CCOC1(OC)C(C)=CC(Cl)C1Cl</smiles>

A thus being an ester-acetal of 2-methyl-4,5,6-trichlorocyclohex-2-en-1-one and glycolic acid.

The formation of such a compound is rather surprising. Apparently 4 atoms of chlorine are added to the benzene ring and one molecule of hydrogen chloride split off with formation of the dioxolone ring: 
$\overbrace{\mathrm{O} \cdot \mathrm{CH}_{2} \cdot \mathrm{COOH}}^{\mathrm{CH}}+2 \mathrm{Cl}_{2} \rightarrow$

Considering the very high rate of the para substitution reaction it is quite unexpected that an addition to the unsubstituted molecule takes place to a measurable extent. It is well-known ${ }^{2}$ that aromatic amines and phenols can, on prolonged chlorination, after completed substitution add chlorine with the formation of highly chlorinated cyclohexenones. If, however, para or ortho substitution had preceded addition of chlorine in the present case the nonaromatic molecule arising from $o$-cresoxyacetic acid by treatment with chlorine, and containing the dioxolone ring, should contain an even number of chlorine atoms, and if a dichloro cresoxy acetic acid had been formed before addition a $>\mathrm{CCl}_{2}$-group should be present in the non-aromatic molecule. The infrared spectrum of the compound seems to exclude this possibility.

The constitution of A given above is based on the following evidence:

1. Quantitative analysis has established the formula $\mathrm{C}_{9} \mathrm{H}_{9} \mathrm{O}_{3} \mathrm{Cl}_{3}$.

2. The ultraviolet absorption spectrum exhibits no bands above $250 \mathrm{~m} \mu$, whereas phenol derivatives have high absorption around $275 \mathrm{~m} \mu$.

3 . In alcoholic solution the compound reacts vigorously with potassium hydroxide with quantitative formation of 4,6-dichloro-2-methyl-phenol. 2 molecules of potassium hydroxide are consumed in the reaction.

4. Metallic zinc removes all chlorine from the compound in boiling alcoholic solution and $o$-cresoxyacetic acid is formed.

5. Anhydrous diethyl amine removes 1 molecule of hydrogen chloride with the formation of a dichloro cresoxyacetic acid, presumably the 5,6-derivative. The compound is different from both the 4,6- and 4,5-dichloro acid.

6 . An aqueous-alcoholic solution of A liberates iodine from potassium iodide with formation of, i.a., 6-chloro-2-methylphenoxyacetic acid. Besides, an oil is formed which is insoluble in aqueous potassium carbonate and thus probably consists of compounds in which the dioxolone ring is intact.

All these reactions are well explained by the constitution proposed above:

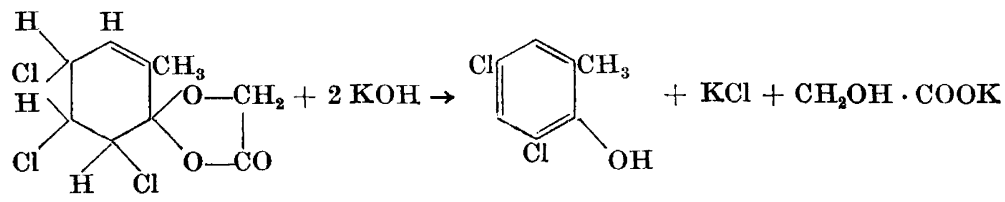

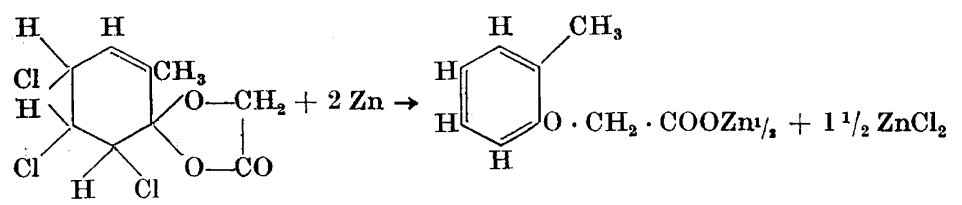




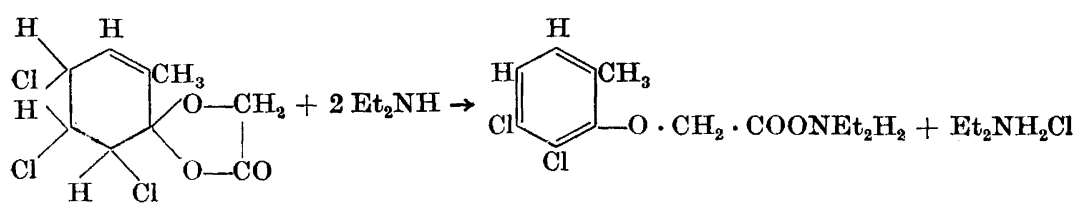<smiles>Cc1cccc(OCC(=O)O)c1OCC(=O)OC12C=CC(C(Cl)C1)C(Cl)C2</smiles>

In the infrared spectrum * an unusually strong absorption band with two peaks at 5.49 and $5.58 \mu$ indicates the presence of a somewhat anomalous carbonyl group. In order to test the absorption band of a carbonyl group in a dioxolone ring the compound $\mathrm{CH}_{3}<\mathrm{O}-\mathrm{CO}_{-\mathrm{CH}}^{\mathrm{O}} \cdot \mathrm{CH}_{3}$ was synthesized from $p$-methylcyclohexanone and lactic acid. Its infrared spectrum contained a similarly intensive band with a peak at $5.59 \mu$. The similarity in intensity and position supports the dioxolone structure in compound $A$.

The formula contains 4 asymmetric carbon atoms in the homocyclic ring and explains the existence of a large number of isomers formed in the addition reaction.

On prolonged boiling in an alcoholic solution of hydrogen chloride compound $\mathrm{A}$, as well as the mixture of isomers, is decomposed with formation of 4,6-dichloro-o-cresol.

\section{EXPERIMENTAL}

1. Isolation of compound $A$. The crude material is heated on a steam bath until completely liquid. $500 \mathrm{~g}$ is poured into $500 \mathrm{ml}$ alcohol and cooled to $10^{\circ}$. The crystals are filtered off, yield about $170 \mathrm{~g}$. They are dissolved in $1200 \mathrm{ml}$ of boiling alcohol and filtered hot from a small amount of inorganic material (sodium chloride) and on cooling to $0^{\circ}$ about $150 \mathrm{~g}$ of pure material, mp. $137^{\circ}$, is obtained. Found: C 39.8; 39.6; H 3.35; 3.28; Cl $39.1 ; 39.0 \% . \quad \mathrm{C}_{9} \mathrm{H}_{9} \mathrm{O}_{3} \mathrm{Cl}_{3}$ requires: $\mathrm{C} 39.76 ; \mathrm{H} 3.34 ; \mathrm{Cl} 39.2 \%$. Equiv.wt. by quantitative saponification with alcoholic potassium hydroxide, indicator methyl red (in order to avoid interference of the cresol): 135.0 ; 135.5; calc. 135.7).

2. Reaction with potassium hydroxide. To a hot solution of A (10 g) in alcohol (75 ml) was added slowly through the condenser $20 \%$ aqueous potassium hydroxide $(30 \mathrm{ml})$. The mixture boiled vigorously without external heating during the addition. Boiling was continued for $15 \mathrm{~min}$. Water was added $(50 \mathrm{ml})$ and the alcohol distilled off. On acidification and cooling 4,6-dichloro-o-cresol separated, yield $6.4 \mathrm{~g}$ (98\% of theory) and was identified by melting point $\left(55^{\circ}\right)$ and by preparation of the corresponding dichloro cresoxyacetic acid (mp. $184-85^{\circ}$ ).

3. Reaction with metallic zinc. To a solution of A (10 g) in boiling alcohol $(75 \mathrm{ml})$ was added zine wool $(7 \mathrm{~g})$. The reduction proceeded rapidly and from the resulting solution $5.0 \mathrm{~g}$ of $o$-cresoxyacetic acid was isolated, m. p. $155^{\circ}$, equiv.wt. by titration 165.5 (calc. 166).

4. Reaction with diethyl amine. To $10 \mathrm{~g}$ of $\mathrm{A}$ was added diethyl amine $(20 \mathrm{ml})$ and the solution was boiled for $15 \mathrm{~min}$. The excess of diethyl amine was distilled off and the

* Thanks are due to professor Børge Bak, Copenhagen, who has taken the infrared spectrograms.

Acta Chem. Scand. 12 (1958) No. 5 
residue dissolved in water and acidified. Yield of crystals $7.5 \mathrm{~g}, \mathrm{mp} .128^{\circ}$. (Found: C $45.7 ; 45.8 ; \mathrm{H}$ 3.33; 3.36; Cl 30.3; 30.4\%; equiv.wt 234. Calc. for $\mathrm{C}_{9} \mathrm{H}_{8} \mathrm{O}_{3} \mathrm{Cl}_{2}$ : $\mathrm{C} 45.9$; H 3.43; Cl 30.2\%; equiv.wt. 235).

4,5-Dichloro-2-methyl-phenoxyacetic acid was prepared from 4,5-dichloro-2-methyl phenol ${ }^{3}$ by condensation with monochloroacetic acid in alkaline solution, $\mathrm{mp} .165-66^{\circ}$, thus evidently different from the acid obtained above, which, therefore, is assigned the 5,6-dichloro structure.

5. Reaction with potassium iodide. To a boiling solution of A (10 g) in alcohol (100 $\mathrm{ml})$ was added an aqueous solution of potassium iodide (10 g). Iodine was slowly liberated and time after time reduced with sodium thiosulfate. After 3 hours' boiling no more iodine was formed. The alcohol was distilled off at diminished pressure and the remaining milky liquid was extracted with ether. The ethereal solution was extracted with aqueous sodium carbonate, from which 6-chloro-2-methyl-phenoxyacetic acid was obtained (mp. $110^{\circ}$ after recrystallization from benzene, equiv.wt. by titration 199.5 , calc. 200.5).

The ethereal solution on evaporation left an uncrystallizable oil which was not examined further.

6. Catalytic hydrogenation of $A$ was attempted (catalyst $\mathrm{PtO}_{2}$ ). The reaction proceeded rapidly at first, but stopped when 2-3 moles of hydrogen had been absorbed. The product, however, still contained chlorine and was obviously a complicated mixture of compounds distilling in vacuo over a very wide range of temperature; further examination was abandoned.

7. Decomposition of $A$ with alcoholic hydrogen chloride. A solution of $15 \mathrm{~g}$ of $\mathrm{A}$ in $10 \%$ alcoholic hydrogen chloride $(60 \mathrm{ml})$ was boiled for $3 \mathrm{~h}$. The alcohol was distilled off at diminished pressure. The oily residue was dissolved in ether and washed with aqueous sodium carbonate, dried, and the ether distilled off. The remaining oil solidified when cooled to $0^{\circ}$. The crystals were identified as 4,6-dichloro-o-cresol.

A similar process was carried out with an amount of the vacuum-distilled mother liquid from the crude product, giving similar results.

\section{REFERENCES}

1. Dan. Pat. 78535 (1946).

2. Zincke, Th. and Schaum, C. Ber. 27 (1894) 537.

3. Zincke, Th. Ann. 417 (1918) 207.

Received November 5, 1957. 